ARTÍCULOS DE INVESTIGACIÓN

\title{
Educación legal y culturas jurídicas: Comparación, trasplantes y resistencias
}

Educação jurídica e culturas jurídica: Comparação, transplantes e resistência

Comparative legal education and legal culture: Trasplants and resistance

Rogelio Pérez-Perdomo

Universidad Metropolitana, Venezuela; Universidad Stanford, Estados Unidos

RESUMEN En el temprano siglo XIX la educación jurídica en Inglaterra y los Estados estaba a cargo de la profesión misma y el método era el de aprendizaje en el oficio. En Europa continental y en América Latina eran las escuelas universitarias de derecho quienes estaban a cargo. En 1870, la Escuela de Derecho de Harvard estableció un currículo dirigido a enseñar el derecho como ciencia, como se hacía en Alemania. El decano Langdell diseñó una estructura e inventó el método de casos y de la discusión en clase como parte de ese proyecto. Ese trasplante tuvo dificultades: el método fue considerado abominable y el número de estudiantes bajó significativamente. Sin embargo, 50 años después Harvard se había convertido en el modelo para las demás escuelas de derecho de Estados Unidos. Hoy las universidades son importantes para la educación jurídica en todos los países del common law. A mediados del siglo XX, varios académicos latinoamericanos se interesaron en la educación jurídica de los Estados Unidos y hubo un esfuerzo por introducir una versión modificada del método de casos haciendo la educación más activa e interdisciplinaria. El trasplante encontró una fuerte resistencia, pero unos 50 años después muchas escuelas de derecho y profesores han adoptado diversas modalidades de este método. El artículo explica el origen histórico de las diferencias y el sentido de la convergencia actual, discutiendo las razones para la resistencia o el éxito de los trasplantes.

PALABRAS CLAVE Educación jurídica common law, educación jurídica, tradición romanista, trasplantes, resistencia.

RESUMO No início do século XIX, a educação jurídica na Inglaterra e nos Estados Unidos era responsável pela própria profissão e o método era o da aprendizagem. Na Europa continental e na América Latina, eram as Escolas de Direito que comandavam. Em 1870, a Harvard Law School estabeleceu um currículo destinado a ensinar direito como ciên- 
cia, como foi feito na Alemanha. Dean Langdell projetou uma estrutura e inventou o método de caso e a discussão em classe como parte desse projeto. Esse transplante teve dificuldades: o método foi considerado abominável e o número de estudantes caiu significativamente. No entanto, 50 anos depois, Harvard tornou-se o modelo para as outras faculdades de direito dos Estados Unidos. Hoje, as universidades são importantes para a educação jurídica em todos os países de direito comum. Em meados do século XX, vários acadêmicos latino-americanos se interessaram pela educação jurídica nos Estados Unidos e houve um esforço para introduzir uma versão modificada do método de caso, tornando a educação mais ativa e interdisciplinar. $O$ transplante encontrou forte resistência, mas cerca de 50 anos depois, muitas faculdades e professores de direito adotaram várias modalidades desse método. $\mathrm{O}$ artigo explica a origem histórica das diferenças e o sentido da convergência atual, discutindo as razões da resistência ou do sucesso dos transplantes.

PALAVRAS-CHAVE Educação jurídica common law, educação jurídica civil law, transplantes e resistência.

ABSTRACT In early 19th century the legal education in England and United States was in charge of the profession and the method was apprenticeship. On the contrary, the university law schools were in charge in continental Europe and Latin America. In 1870 Harvard Law School established a curriculum addressed to teach law as a science, as it was done in Germany. Dean Langdell designed a structure and invented the case method and class discussion as part of this project. The transplant had severe difficulties, the number of students dropped and the method was considered abominable, but 50 years later most law schools have adopted it in United States and later in other common law countries. By mid $20 t h$ century, Latin American law schools started looking at their United States counterparts and tried to transplant the case method. The transplant found stiff resistance, but by late 2oth century many schools and professors have adopted a modified version of the case method and active class, but the resistance is still present. The article analyzes these histories, and the reason for resistance or success of these transplants.

KEYWORDS Legal education common law, legal education civil law, transplants, resistance.

\section{La formación de los profesionales del derecho y la cultura jurídica}

El tema de este artículo es la educación jurídica como parte de la cultura jurídica o en su relación con ella. Cultura jurídica es un término polémico, ya que puede tener varios significados y usos. Atengámonos al mencionado por Lawrence Friedman,

1. Este artículo fue originariamente preparado como conferencia para ser pronunciada en la Facultad del Derecho de la Universidad de Chile el 11 abril 2019. Esta versión se ha beneficiado de los comentarios de profesores y estudiantes chilenos, en particular de los profesores Agustín Barroilhet, María Francisca Elgueta y Andrés Cúneo. 
quien fue el primero en usarlo: las actitudes, valores, conocimiento y opiniones que tenemos sobre el derecho o sistema jurídico (Friedman, 1975: 194 ss.). En ese sentido todos tenemos una cultura jurídica, pero puede haber diferencias importantes dependiendo de nuestra nacionalidad, educación y ocupaciones. Por ejemplo, la cultura jurídica de los profesores universitarios puede tener diferencia con la de los militares y la de los suizos probablemente es distinta a la de los venezolanos. No obstante, no hay nada misterioso en la cultura jurídica: podemos analizarla apoyados en estudios de opinión (los más frecuentes), de actitudes o de una manera más interesante pero más incierta a través de la literatura de ficción o el cine. Esto ocurre de la misma manera en relación con otros aspectos de la cultura: todos tenemos una cultura musical. Hay musicólogos, virtuosos tocando un instrumento y otros que solo escuchamos música para disfrutarla. Algunos prefieren Mozart, otros el rock duro.

De una manera general puede distinguirse entre la alta cultura y la común. Los chefs de cocina y los reconocidos como gourmets tienen una alta cultura gastronómica, versus todos los demás. En el derecho habría que distinguir entre la cultura de los profesionales del derecho y los demás mortales. Los profesionales del derecho conocen mejor los principios y reglas del derecho, pueden entender mejor el arcano lenguaje de la legislación, de las decisiones judiciales y de los libros de derecho y, sin duda, tienen actitudes y opiniones sobre el sistema jurídico, jueces y abogados distintos a los de otros sectores de la población. Friedman la llama la cultura jurídica interna, pero podemos llamarla también cultura jurídica profesional. Los chistes sobre abogados muestran que el público general desconfía de ellos, una muestra de un cierto choque cultural (Galanter, 2005).

Lo que hace la diferencia entre la cultura jurídica general y la cultura profesional - o alta cultura jurídica - es la educación legal. Los profesionales pasan por períodos más o menos largos de formación intelectual y de entrenamiento ocupacional que los proveen de conocimientos y destrezas que los distinguen del resto de la sociedad. En otras palabras, lo que distingue a los profesionales del derecho del resto de los mortales es que tienen una educación específica que los provee de conocimientos y destrezas específicas: lenguaje, formas de razonamiento, maneras de abordar problemas, conocimiento de las reglas de derecho y de cómo moverse dentro de su aparato. Por supuesto, la manera como se adquieren estas destrezas, conocimientos y valores varía de una sociedad a otra y de una época a otra, y el resultado que produce en las personas que se someten a ella es diferente. De allí que los estudios sobre la educación jurídica sean tan importantes para el estudio de los profesionales del derecho.

La adquisición de una cultura profesional no borra la cultura general, no convierte a los profesionales del derecho en extraterrestres. Conocen las prácticas sociales, se desenvuelven en ambos mundos culturales y, mal que bien, logran integrarlos. Los profesionales del derecho de éxito conocen no solo las reglas formales del derecho, sino también las informales de funcionamiento del aparato jurídico, y además en- 
tienden los negocios que asesoran y las prácticas sociales del mundo en que se mueven. De ahí que se preste atención al contexto y que el estudio puramente normativo del derecho lo consideremos fatalmente defectuoso: la cultura jurídica profesional es algo más que el mero conocimiento de las leyes y precedentes judiciales.

En esta conferencia me referiré en primer lugar a la tradición jurídica romanista, que es la nuestra. Con esto introduciremos un nuevo término, el de tradición jurídica. Usaremos la definición de John H. Merryman y Pérez-Perdomo, quienes mencionan que:

Es el conjunto de las actitudes con respecto a la naturaleza del derecho y su papel en la sociedad y la política que están profundamente arraigadas y condicionadas históricamente. Incluye la manera como el derecho debe ser hecho, aplicado, estudiado, perfeccionado y enseñado. La tradición jurídica es la parte más consolidada y permanente de la cultura jurídica, especialmente de la profesional (2019: 2).

\section{La educación en la tradición jurídica romanista y en América Latina}

Para nuestros propósitos hay dos momentos a destacar: en el siglo XII se crearon los estudios de derecho en la Universidad de Bolonia que se extendieron por Europa con relativa rapidez. Fueron los estudios de derecho y los de teología, considerados los más importantes en la época, los que configuraron originalmente las universidades. Tanto Bolonia como París fueron los centros universitarios originales y, en cierta forma, se concentró una en derecho y la otra en teología. En España, en el siglo XIII, se creó la Universidad de Salamanca, que incluía estudios jurídicos en el estilo de Bolonia. En las «Siete Partidas» - un documento del siglo XIII - los abogados debían ser «sabidores de derecho» (partida III, título VI), pero no necesariamente graduados universitarios. En el siglo XVI ya había un número de graduados en derecho y los reyes católicos establecieron los estudios universitarios de derecho como requisito para que los tribunales pudieran aceptar a los abogados. En la América española se crearon universidades con estudios de derecho a mediados del siglo XVI en Santo Domingo, México y Perú. Al final de ese siglo ya había un pequeño número de abogados graduados en derecho y a finales del siglo XVIII había preocupación porque se consideraba que había muchos abogados (Pérez-Perdomo, 2006).

Podría designarse como trasplantes esta difusión de los estudios de derecho, primero a España y luego a la América española, pero eran trasplantes sin resistencia porque no había otra forma organizada de aprender derecho. Es bueno advertir que, aun cuando se reservó el título de abogado para los graduados universitarios, personas que no tenían estos títulos podían desempeñar tareas jurídicas como redactar documentos o hacer gestiones en los tribunales. Quienes eran autorizados por un tribunal eran denominados procuradores y los no-autorizados eran conocidos como 
tinterillos o pica-pleitos. Claramente los abogados tenían un estatus social muy superior a los procuradores y tinterillos, y los desplazaban si lo deseaban, aunque los tinterillos, justamente por ser frecuentemente "pardos» socialmente podían relacionarse más fácilmente con clientes de medios modestos (Lira González, 1984). En todo caso, como procuradores y tinterillos no estaban organizados y carecían de prestigio social no pudieron oponer resistencia a la implantación de estudios universitarios de derecho. Hacia 1800 el número de abogados había crecido lo suficiente como para que el Consejo de Indias se preocupara por su número y pidiera a las distintas audiencias información sobre el número de abogados en sus distritos (Pérez-Perdomo, 2006).

En los siglos XIX y XX en las nuevas repúblicas latinoamericanas, los estudios de derecho crecieron en importancia. Los abogados progresivamente desplazaron a los procuradores y tinterillos hasta hacerlos desaparecer. De una manera más general, puede afirmarse que lo característico de nuestra tradición jurídica es que los profesionales del derecho son formados por las universidades. En otras palabras, las universidades cumplen la función de contralores al ingreso en la profesión. Todavía más importante que esto, las escuelas universitarias de derecho tenían la función de formar la elite política al menos hasta mediados del siglo XX. La mayor parte de los legisladores y de quienes ejercían altos cargos políticos estudiaban derecho. No era un requerimiento formal, pero ayudaba.

Los estudios universitarios de derecho se transformaron. Al derecho romano y el canónico, que constituyeron el eje de los estudios jurídicos hasta el siglo XVIII, se agregaron los de derecho natural, derecho constitucional (o derecho político, como se lo llamó en la época), derecho internacional público, derecho administrativo y economía política, entre otras materias que en la época se consideraron apropiadas para formar la elite política. Tanto el derecho constitucional como el derecho internacional público no se consideraban relacionados con la práctica del derecho. Desde la segunda mitad del siglo XIX los códigos y la literatura exegética ocuparon un lugar central en los estudios de derecho. Se consideró que la comprensión y hasta la memorización del contenido de los códigos preparaba adecuadamente para el ejercicio profesional. En el curso del siglo XX influyó un pensamiento que consideró que podía ordenar de una manera más racional el contenido de los códigos y en general de la legislación. Producto de este pensamiento más conceptual surgieron los manuales para la enseñanza del derecho. La presencia del derecho canónico se debilitó hasta desaparecer en la mayor parte de los planes de estudio. En cambio, el derecho administrativo, el tributario y el laboral tomaron un lugar importante. Esto es una apretada síntesis de un campo que permanece poco explorado: la historia de la educación jurídica y de la literatura didáctica en derecho (Jamin, 2011; Pérez-Perdomo, 2006).

Vistas desde la actualidad, las escuelas de derecho de América Latina fueron muy pobres. Sus bibliotecas eran pobres, los profesores eran abogados, jueces o funcionarios que solo dedicaban una fracción de su tiempo a ofrecer clases en las universida- 
des, y la mayor parte de los estudiantes lo eran también a tiempo parcial. Sin embargo, el grado en derecho era una especie de carnet de pertenencia a la elite intelectual y política. La explicación de esta aparente paradoja está en el contexto. Las personas que llegaban a la escuela de derecho tenían una formación familiar y colectiva relativamente sólida porque se apreciaba el buen decir y la escritura correcta. Muchos abogados eran provincianos que estudiaban en la capital o en las pocas ciudades donde había universidades. Lo usual era que los estudiantes se reunieran para conversar sobre lecturas o sobre política. En las biografías de los abogados (todos hombres) del siglo XIX y de comienzos del siglo XX se destacaba su porte elegante, su elocuencia, la escritura florida y otras cualidades por el estilo. Como durante los estudios de derecho los estudiantes trabajaban en los estudios de abogados o en los tribunales, se graduaban bastante bien preparados para el ejercicio profesional. La pobreza de las escuelas de derecho era compensada por el contexto y por un nivel cultural más pobre en el resto de la sociedad.

A mediados del siglo XX la ilusión se desvaneció. Las limitaciones de las escuelas de derecho empezaron a hacerse evidentes y se habló de la necesidad de su reforma. Dantas, un eminente jurista brasileño, pronunció en 1955 una requisitoria elocuente. Según el autor, la explicación y memorización de códigos tenía muy poca utilidad para formar abogados. Más adelante volveremos sobre sus postulados. Al final de la década de 1960, los reformistas fueron apoyados por un grupo de profesores de los Estados Unidos en lo que se llamó el Movimiento de Derecho y Desarrollo. Los profesores americanos se presentaron como misioneros del método de casos y de una visión más instrumental del derecho. Fue un esfuerzo de trasplante del método de casos a América Latina. La resistencia a las reformas propuestas fue frontal. Los misioneros se declararon vencidos y regresaron derrotados a sus bases (Trubek y Galanter, 1974), pero la historia no terminó ahí (Pérez-Perdomo, 2006). La retomaremos más adelante. Antes debemos ver la educación jurídica en el common law, y especialmente, en los Estados Unidos.

\section{La tradición del common law y la innovación americana}

Hacia 1850 tal vez la distinción más importante entre el common law y la tradición romanista estaba en la educación jurídica: en Inglaterra y en los Estados Unidos era la propia profesión la encargada de formar a sus miembros y las universidades no tenían un papel importante en ese proceso. Esto requiere una breve explicación. Desde el siglo XIII, Inglaterra contaba con universidades prestigiosas donde se enseñaba el derecho romano y el canónico, como en el resto de Europa. Como estos abogados se formaban estudiando el Corpus iuris civilis de Justiniano se los denominaba civil lawyers (Brundage, 2008). Tenían el privilegio de litigar en el más alto tribunal, la Corte de Equity, la Court of Chancery. Era un tribunal donde se podía buscar reme- 
dio para los asuntos en que los tribunales reales resultaban inadecuados, especialmente por las rigideces procesales del common law o derecho real común para toda Inglaterra. En la llamada Revolución Gloriosa de final del siglo XVII, los civil lawyers perdieron su privilegio y muy pronto casi todos los abogados de Inglaterra fueron common lawyers. Estos eran formados por la profesión con la ayuda de unas instituciones llamadas inns of courts, donde se comía en común y se socializaba. Hasta prácticamente el presente, un requerimiento formal importante en la formación de los abogados litigantes (los barristers) era un cierto número de comidas en la inn of courts de adscripción. Esta manera de educar era muy fuerte en la socialización de los nuevos abogados, aunque no lo era en la transmisión de conocimientos y destrezas (Brooks, 1998; Prest, 1967). Los jóvenes aspirantes debían adquirir los conocimientos por lecturas y la destreza ayudando en el manejo de casos a los barristers ya establecidos.

Los barristers estaban sometidos a una serie de restricciones ocupacionales. No podían tratar directamente con los clientes. Eran los solicitors, la rama menor de la profesión, quienes atendían a los clientes y trataban del caso con los barristers, quienes comenzaban a tener buenos casos y ganar buen dinero solo cuando eran conocidos entre los solicitors. Esto hacía que solo las personas con propiedades importantes aspiraran a ser barristers. Los jueces de los tribunales importantes (crown courts) eran seleccionados solo entre los barristers de mayor rango, los queen's counsels.

Esta manera compleja y aristocrática de formar a los profesionales del derecho no se transfirió a las colonias americanas, que carecían de la base aristocrática. Los abogados en los Estados Unidos eran formados por otros abogados o por sí mismos. Había abogados que tenían una formación humanista adquirida en los estudios liberales de las universidades y se habían formado en el oficio que buenos abogados, pero había otros eran gravemente ignorantes. Hacia 1800 surgieron las llamadas escuelas de propietarios, que no eran más que extensiones de la oficina de un abogado con vocación de educador. Estas escuelas no expedían títulos, sino una carta que certificaba que una persona determinada había leído sobre derecho por un determinado período. El abogado-profesor básicamente ayudaba con sus explicaciones en la lectura de libros fundamentales como el de Coke o Blackstone.

Las universidades, tanto en Inglaterra como en Estados Unidos, eran pensadas como centros de formación humanística y los estudios de derecho (fundamentalmente derecho romano) eran parte de esa formación humanística, pero el derecho a ser aplicado en la práctica no se enseñaba universitariamente. Hubo esfuerzos para que las universidades asumieran la enseñanza del derecho, pero no tuvieron éxito. En el siglo XVIII Oxford creó una cátedra de derecho inglés y Blackstone fue su primer profesor. Rápidamente Comentarios al derecho de Inglaterra se convirtió en una obra fundamental, aunque mucho más leída en los Estados Unidos que en Inglaterra. La cátedra cayó en el sopor de un siglo hasta que fue designado Albert Dicey y Oxford 
hizo un esfuerzo de crear una verdadera escuela de derecho. Como en otras partes de Europa se enseñó también derecho internacional y filosofía del derecho. Dicey (1883) tiene un estremecedor artículo sobre si se puede enseñar derecho en las universidades que critica ferozmente la manera inglesa de educación por la profesión. Su conclusión fue que el derecho puede y debe ser enseñado en las universidades.

Por supuesto, el obstáculo mayor para convertir al derecho en un estudio universitario en Inglaterra venía de la profesión organizada que tenía prestigio social y poder político. Oxford, y Dicey en particular, encontraron este obstáculo formidable (Abel-Smith y Stevens, 1967; Lawson, 1968). Este fue un claro caso de resistencia que solo fue vencido en la segunda mitad del siglo XX.

Ese obstáculo no existía en los Estados Unidos. Otro obstáculo era la concepción de las universidades como centros de estudios humanísticos. En el siglo XIX, en los Estados Unidos, tomó fuerza la idea de que la universidad debían ser un centro de enseñanza científica y profesional también. Varios innovadores universitarios llegaron a dirigir los nuevos tipos de universidades. Entre ellos Charles Eliot, quien decidió renovar a Harvard bajo ese nuevo modelo de universidad y llamó a Langdell como profesor y decano de derecho con el propósito de que convirtiera el estudio del derecho en algo científico, como había observado que sucedía en Alemania. Langdell no estaba familiarizado con la educación jurídica alemana, pero claramente era una persona creativa. Le dio particular rigor a los estudios de derecho: los hizo de posgrado, introdujo los exámenes anónimos, se creó la revista de derecho dirigida por los estudiantes e inventó el llamado «método de casos» (case method), tal vez su invención más notoria y polémica. En realidad, es una interpretación peculiar de los casos: la idea era discutir sentencias de tribunales de apelación previamente seleccionadas y editadas por el profesor. Este debía dirigir una discusión que condujera a los estudiantes a descubrir los principios que comandaban la decisión. Supuestamente era un método inductivo, el salón de clase era el laboratorio y la biblioteca la fuente primaria de información.

No vamos a entrar en lo discutible de la concepción de ciencia de Langdell. Nadie la defendería hoy. Pero después de un comienzo difícil en que la escuela de derecho de Harvard perdió estudiantes, las virtudes educativas se pusieron de manifiesto (Coquillette y Kimball, 2015). Dicey visitó a Harvard y describió el método de enseñanza. Le hizo grandes elogios a lo que Harvard realizaba (1900). Los graduados en Harvard fueron especialmente hábiles en hacer distinciones y en argumentar, y se expresaban oralmente y por escrito con precisión. Las nacientes grandes firmas de abogados los preferían para contratarlos y en pocas décadas las otras escuelas de derecho comenzaron a contratarlos como profesores, lo que contribuyó a la difusión del modelo en los Estados Unidos. Hacia 1920, el liderazgo de Harvard era indiscutible y todas las escuelas de derecho del país seguían su modelo (con mayor o menor éxito), a pesar de que ninguna autoridad pública intervino (Stevens, 1983; Friedman, 2002). 
En los últimos cien años mucha agua ha corrido (Gordon, 2007). «Caso» significa algo completamente distinto a lo planteado por Langdell y Harvard a final del siglo XIX. Harvard sigue siendo una excelente escuela de derecho, pero no tiene la absoluta primacía que tuvo en el pasado. Por otra parte, las escuelas de derecho de Estados Unidos tienen liderazgo en educación jurídica mundialmente, lo que se ve reflejado en los millares de estudiantes de muchos países que cada año van a los Estados Unidos a estudiar en alguno de los diversos programas que ofrecen las escuelas de derecho. Lo que nos interesa destacar aquí es que la educación universitaria en derecho fue un exitoso trasplante. Primero pasó de Alemania a los Estados Unidos y luego a los demás países del common law, incluida Inglaterra. Como veremos a continuación, las innovaciones que se hicieron en los Estados Unidos ahora se las mira en el resto del mundo. Son millares los abogados de los países de la tradición romanista que van a hacer estudios en las escuelas de derecho de los Estados Unidos y muchas escuelas están incorporando elementos de la educación jurídica que fueron desarrollados primero en ese país. ¿Estamos en presencia de un trasplante de vuelta?

\section{Trasplantes, resistencias y globalización}

En resumen, la educación jurídica en las universidades se ha impuesto en el mundo. Lo ha hecho porque las universidades pueden transmitir mucho más que una práctica y facilitar la socialización en una profesión. Todavía a comienzos del siglo XX se discutía en el mundo anglo-americano. Veblen (1918), un sociólogo que todavía admiramos por su estudio de la clase ociosa, consideraba tan absurdo enseñar derecho en las universidades como enseñar a bailar.

En la década de 1930 varios académicos europeos se interesaron en la educación jurídica de los Estados Unidos. Constataron avances importantes y también que no estaba a la altura del nivel que había alcanzado en Francia (Valeur, 1928) o Alemania (Rheinstein, 1938). América Latina cambió el relato a mediados del siglo XX. En 1955, Dantas, un jurista e intelectual brasileño de una enorme influencia, habló de la crisis de la educación jurídica de Brasil, y sus afirmaciones eran extensibles a América Latina y también a varios países de Europa. Dantas constató que el estudio de los códigos y los principios y conceptos del derecho no estaban contribuyendo a formar buenos abogados y que el mercado internacional de la abogacía estaba dominado por las firmas de los Estados Unidos y por los abogados americanos. Propuso que se introdujera el método de casos, la dimensión interdisciplinaria del derecho y la clase activa o de intensa participación estudiantil (Dantas, 1955). Miraba a los Estados Unidos, pero no a la ortodoxia langdelliana, que no tenía nada de interdisciplinario. Sin duda, miraba a lo que estaban haciendo los profesores de dos movimientos en boga, la jurisprudencia sociológica y los realistas. La escuela de derecho de Harvard 
había encontrado una fuerte competidora en Yale. Probablemente, Dantas estaba mirando más a Yale que a Harvard.

Merryman (1975) hizo una apreciación similar a la de Dantas mirando la educación jurídica en Italia y Chile, que él extendió a toda la tradición romanista. La comparó con la educación jurídica de los Estados Unidos, aunque realmente se refería a Stanford. La escuela de derecho de Stanford de la época tenía al menos dos rasgos distintivos: era pequeña y la relación entre estudiantes y profesores era menos jerárquica que en la Costa Este; y hacía un esfuerzo de interdisciplinariedad y de internacionalización. En la década de 1970 ofrecía cursos de derecho comparado y cursos más específicos sobre cómo funcionaba el derecho en la Unión Soviética en China, en Italia, en determinados países de África y entre los zapotecas (México). Mauro Cappelletti y Bryant Garth (1978) dirigieron el programa de acceso a la justicia, de alcance global. Hubo también un programa con la India y otro con Chile (Merryman, 2000). Merryman, Friedman y Clark (1970) estuvieron a cargo del Stanford Program for Law and Development, que reunió datos y analizó la relación entre el derecho y cambio social en España, Italia, Chile, Perú, Costa Rica y Colombia. La Escuela de Derecho de Stanford desarrolló igualmente los cursos en simulación y las clínicas jurídicas (Méndez, 2008). En la segunda mitad del siglo XX Stanford se convirtió en una de las principales escuelas de derecho de los Estados Unidos y, en lo que va de este siglo, se ha convertido en una de las más innovadoras con una vocación internacional y una audiencia global. Merryman seguramente se excedió al generalizar la experiencia de Stanford en esa época, pero la dirección que tomó Stanford es ahora más compartida.

¿Cuál es el encanto de las escuelas de derecho de los Estados Unidos que atraen a un público universal? Destaco tres aspectos. El primero es que no se concentraron en enseñar un derecho nacional. Harvard, Yale o Stanford nunca se han concentrado en el derecho de Massachusetts, Connecticut o California. Segundo, la flexibilidad: el programa inicial (el Juris Doctor, o JD) fue el dedicado a formar abogados, pero luego inventaron los másteres y doctorados, que han adaptado bastante bien para los estudiantes extranjeros. Tercero: la innovación constante. Stanford se ha interesado en particular por la educación interdisciplinaria, internacional, con atención a desarrollar los aspectos éticos, la escritura, la investigación, la negociación y otras competencias. También tanto a aplicar nuevas tecnologías como estudiar los desafíos que plantea al derecho (Pérez-Perdomo, 2018).

A estos aspectos intelectuales y organizativos debe agregarse que Estados Unidos invierte mucho en educación universitaria, especialmente en las escuelas de derecho. Una de las tareas principales de los decanos, sino la principal, es buscar fondos. Los egresados son una fuente muy importante. Esto les permite dotarse de excelentes infraestructuras, bibliotecas, pagar salarios competitivos a sus profesores y becar o prestar dinero a los estudiantes para que se dediquen a tiempo completo. Así la exigencia académica con profesores y estudiantes puede ser muy alta. 
La educación jurídica en los países de la tradición romanista ha sido sacudida en nuestra época. Tal vez nadie mejor que Damaska (1968) ha descrito lo que podía lograr una buena escuela de derecho, con buenos profesores y buenos estudiantes. Los profesores ofrecían una visión bien organizada de una rama del derecho en un país determinado y un lenguaje preciso para manejarla. Una buena clase magistral puede también ser motivadora y lograr un cierto entusiasmo por la disciplina. En otras palabras, las escuelas que hoy llamamos tradicionales pueden graduar personas con un buen conocimiento de los principios y reglas de un sistema jurídico. La época en que vivimos de interacciones internacionales muy intensas, de invención frecuente de formas para adaptarse a desafíos sociales y tecnológicos requiere otras competencias. El papel que han tenido muchos abogados y hasta profesores distinguidos en graves violaciones de los derechos humanos y en grandes escándalos de corrupción, muestra que se descuidó la formación ética para privilegiar al derecho establecido. El aprendizaje ético y la adquisición de destrezas de cómo investigar, expresarse adecuadamente o negociar no se puede lograr con clases magistrales ni proveyendo información, por bien organizada que esta sea.

En Europa, el proceso de integración ha sacudido la educación centrada en proveer conocimientos sobre el derecho nacional, pero el paso a una educación más centrada en competencias, más interdisciplinaria, más internacional y con mayor participación de los estudiantes, con una discusión que no descuide la dimensión ética del derecho, ha encontrado resistencias entre los profesores (Heringa, 2011; Heringa y Akkermans, 2011). Las escuelas de derecho de Maastrich y la Bucerius en Hamburgo están entre las innovadoras. En Francia, la resistencia de las universidades ha sido tal vez mayor y fue el Institute de Sciences Politiques el que decidió crear una escuela de derecho que responde a la sociedad compleja y globalizada del presente (Jamin, 2012). En España, el Instituto Empresa también creó una escuela de derecho de propósitos innovadores. La polémica sigue, pero el campo de la educación jurídica está lejos del sopor que vivió hace un siglo.

¿Cómo estamos en América Latina? Puede decirse que Dantas hizo sonar la alarma. Luego, en la década de 1960, varias conferencias de decanos y directores de escuela aprobaron acuerdos por la introducción de diversos tipos de innovación con pocos resultados prácticos. A final de la década y comienzos de la siguiente, la presencia de los profesores-misioneros del movimiento de derecho y desarrollo removió las aguas. Mucho de la polémica se centró en el método de casos. La clase del profesor y la transmisión de conocimientos sobre el derecho nacional se vio como inherente a la tradición romanista y como algo intocable de nuestra cultura jurídica. La realidad es que esas características habían sido innovaciones en el siglo XIX: hasta ese siglo el derecho no fue concebido como un saber nacional y se usaban las «disputas» o discusión de problemas como uno de los métodos. Fue la falta de investigación histórica en la materia lo que llevó a plantear ciertos rasgos desarrollados en el siglo XIX como 
esenciales a nuestra tradición. Tampoco había mucha información comparatista: en Alemania nunca se dejaron de usar casos, aunque no tuvieron la relevancia que han tenido en los Estados Unidos.

La resistencia no determinó que la historia se detuviera. Las innovaciones expulsadas por la puerta se introdujeron por la ventana gracias a la iniciativa de algunos decanos y profesores. Así se introdujo la clínica jurídica, cursos de simulación para el entrenamiento en litigio o en negociación. Algunos profesores y escuelas comenzaron a usar casos y cursos más interactivos, con discusión de aspectos éticos, sociales y económicos del derecho. La materia de derechos humanos se ha privilegiado en algunas universidades (González Mantilla, 2008; Zolezzi Ibárcena, 2017; PérezPerdomo, 2006).

Seguramente ayudó que las necesidades de la globalización y el auge de las escuelas norteamericanas de derecho atrajeron a un buen número de abogados latinoamericanos, facilitando la comparación, diferentes aproximaciones al derecho y diversos métodos educativos. También ha ayudado que se ha creado un buen número de escuelas de derecho interesadas en competir con las más establecidas y que en algunas escuelas de larga historia grupos de profesores, especialmente alertas y activos, han introducido innovaciones diversas. Sospecho que ha habido más innovación educativa en América Latina que en Europa. Una muestra indicadora de este renovado interés por la educación jurídica es la regularidad de la aparición de las revistas Academia, Revista sobre Enseñanza del Derecho, y Pedagogía Universitaria y Didáctica del Derecho, ambas creadas en los últimos veinte años. La globalización también ha influido en la rápida expansión del modelo de las grandes firmas internacionales de abogados. Estas firmas requieren abogados preparados de la nueva manera, acostumbrados a lidiar con distintas culturas jurídicas y enfocar los problemas más interdisciplinariamente. Ha sido la presión de las firmas de abogados, junto con el proceso de Bolonia, lo que está impulsando el cambio en Europa.

La modesta buena salud de la renovación de la educación jurídica en América Latina y, en cierta medida, en Europa y otras partes del mundo, no debe dejar de considerar las fuentes de la resistencia. Los cambios en la educación jurídica, especialmente en el ámbito de los métodos educativos, implica una transformación del papel del profesor. La transformación de roles afecta la identidad, de ahí la persistencia de viejos hábitos y de formas educativas que ya no son defendidas teóricamente. No se trata solo de trasplantes de métodos desarrollados en escuelas de derecho de los Estados Unidos, sino en otras disciplinas. La simulación, por ejemplo, se usa muy intensamente en las escuelas de negocios, y la educación clínica en las escuelas de medicina. La Unión Europea y los ministerios de educación de Europa están llamando a quitarle primacía a la transmisión de conocimientos y favorecer la formación de competencias. Pero aun cuando hay una coalición tan amplia que nos llama a revisar nuestros métodos educativos, no es una tarea fácil. El método educativo implica un 
cambio de roles del profesor, lo que afecta su identidad. Generalmente implica también una relación más cercana con los estudiantes. Todo esto puede resultar muy amenazante para quienes se hayan educado de una manera tradicional. No debe sorprendernos que estos cambios estén tomando más tiempo que el trasplante desde la tradición romanista a los Estados Unidos, ya que la tardanza no significa que haya fracasado. Al contrario, hay quienes ven que el nuevo estilo es el triunfante, como lo plantea Dezalay y Garth (2002), pero a diferencia de estos distinguidos autores, no veo guerras de palacio ni luchas por el poder político, sino conflictos mucho más existenciales y profundos para quienes hemos estado involucrados en ellos. Los métodos educativos afectan la manera en que los profesores se ven a sí mismos y entienden tanto su papel como su relación con los estudiantes.

Un elemento que puede ser muy importante es la reacción de la profesión. En Inglaterra, la profesión organizada fue la fuente de resistencia a la introducción de la educación jurídica por las universidades. En Estados Unidos, que no tenía una profesión organizada al estilo inglés, las grandes firmas de abogados al preferir los graduados en ciertas escuelas han sido fuente de competencia entre las escuelas y de innovación. En América Latina la creciente globalización de los abogados de negocios (Gómez y Pérez-Perdomo, 2018) y en otras áreas como derechos humanos ha comenzado a poner presión sobre la educación jurídica. Todo nos lleva a pensar que esta última será un tema de creciente atención, y que seguiremos observando esfuerzos de cambio, de trasplantes y de resistencia.

\section{Referencias}

AbEL-SMith, Brian y Roberts Stevens (1967). Lawyers and the courts. Londres: Heineman. BRooks, Christopher (1998). Lawyers, litigation and English society since 1450. Londres: Hambledon Press.

BRUNDAGE, James (2008). The medieval origins of the legal profession. Canonists, civilians, and courts. Chicago: University of Chicago Press.

Cappelletti, Mauro y Bryant Garth (1978). Access to justice. Milán: Giuffrè.

Coquillette, Daniel y Bruce Kimball (2015). On the battlefield of merit. Harvard Law School, the first century. Cambridge: Harvard University Press.

DAmAsKa, Mirjan (1968). «A continental lawyer in an American law school: Trials and tribulations of adjustment». University of Pennsylvania Law Review, 116 (8): 1363-1378. Disponible en https://bit.ly/34bIgGZ.

DANTAS, Santiago (1955). «A educação jurídica e a crise politica brasileira». Revista Forense, 59.

Dezalay, Yves y Bryant Garth (2002). The internationalization of palace wars: Lawyers, economists ant the contest to transform Latin American states. Chicago: Chicago University Press. 
DiCEY, Albert (1883). Can English law be taught at the universities? Londres: Macmillan. Dicey, Albert (1900). "The teaching of English law at Harvard». Harvard Law Review, 13 (5): 422-440. Disponible en https://bit.ly/34bcdHn.

Friedman, Lawrence (1975). The legal system. A social science perspective. Nueva York: Russel Sage.

-. (2002). American law in the 2oth century. New Haven: Yale University Press.

Galanter, Marc (2005). Lowering the bar: lawyer jokes and legal culture. Madison: University of Wisconsin Press.

Gómez, Manuel y Rogelio Pérez-Perdomo (2018). «Corporate lawyers and multinational corporations in Latin America and Spain: 1990-2015». En Manuel Gómez y Rogelio Pérez-Perdomo (editores), Big law in Latin America and Spain. Globalization and adjustments in the provision of high-end legal services (pp. 3-24). Londres. Palgrave Macmillan.

González Mantilla, Gorki (2008) La enseñanza del derecho o los molinos de viento. Cambios, resistencias, continuidades. Lima: Palestra y Pontificia Universidad Católica del Perú.

Gordon, Robert W. (2007). «The geological strata of the law school curriculum». Vanderbilt Law Review 6o (2): 339-368. Disponible en https://bit.ly/2rHW4ff.

Heringa, Aalt Willem (2011). «European legal education or legal education in Europe». Maastricht Journal of European and Comparative Law, 18 (3): 221-224. DOI: 10.1177/1023263X1101800301.

Akrermans, Bram y Aalt Willem Heringa (2011). Educating European lawyers. Cambridge: Intersentia.

JAMIN, Cristophe (2011). «Le droit des manuels de droit ou l'art de traiter la moitié du sujet. En Anne-Sophie Chambost (directora), Histoire des manuels de droit: Une histoire de la littérature juridique comme forme du discours universitaire (pp. 127155). París: Librairie Générale de Droit et Jurisprudence.

-. (2012). La cuisine du droit. L'École de Droit de Sciences Po: Une expérience française. París: Lextenso.

Lawson, Frederick (1968). The Oxford Law School 1850-1968. Oxford: Clarendon Press.

Lira GonzÁlez, Andrés (1984). «Abogados, tinterillos y huizacheros en el México del siglo XIX». En Jorge L. Soberanes Fernández (editor), Memoria del III Congreso Mexicano de Historia del Derecho (pp. 375-392). México: Universidad Nacional de México.

Méndez Longoria, Miguel (2008). «Innovación pedagógica temprana en la Escuela de Derecho de Stanford». Cuadernos Unimetanos, 15: 108-127. Disponible en https://stanford.io/2Pd97hJ.

Merryman, John Henry, Lawrence Friedman y David Clark (1970). Law and social change in Mediterranean Europe and Latin America: a handbook of legal and social indicators for comparative study. Nueva York: Oceana. 
Merryman, John Henry (1975). «Legal education there and here. A comparison». Stanford Law Review, 27 (3): 859-878. Disponible en https://bit.ly/2YEybRS.

-. (2000). «Law and development memoirs I: The Chile law program». American Journal of Comparative Law, 48 (3): 481-499. Disponible en https://bit.ly/2PC5EYY. Merryman, John Henry y Rogelio Pérez-Perdomo (2019). The civil law tradition. $4^{\mathrm{a}}$ ed. Stanford: Stanford University Press.

Pérez-Perdomo, Rogelio (2006). Latin American lawyers: A historical introduction. Stanford: Stanford University Press.

-. (2018). «De Harvard a Stanford: Sobre la historia de la educación jurídica en los Estados Unidos». Boletín Mexicano de Derecho Comparado, 51 (151): 313-358 Disponible en https://bit.ly/2Pfcogr.

Prest, Wilfred (1967). «Legal education of the gentry at the inns of courts, 15601640». Past and Present, 38 (1): 20-39. Disponible en https://bit.ly/2RHdinH.

Rheinstein, Max (1938). «Law faculties and law schools. A comparison of legal education of legal education in the United States and Germany». Wisconsin Law Review: 5-42. Disponible en https://bit.ly/36uSQdU.

Stevens, Robert (1983). Law school. Legal education in America from 1850 so the 1980s. Chapel Hill: The University of North Carolina Press.

TRUBEK, David y Mark Galanter (1974). «Scholars in self-estrangement: Some reflections on the crisis in law and development studies in the United States». Wisconsin Law Review: 1062-1103. Disponible en https://bit.ly/2rEyWyd.

VAleur, Robert (1928). The enseignement du droit en France et aux États-Unis. París: Marcel Giard.

Veblen, Thorstein (1918). The higher learning in America: A memorandum on the conduct of the universities by business men. John Hopkins University Press.

Zolezzi IbárCena, Lorenzo (2017). La enseñanza del derecho. Lima: Fondo Editorial Pontificia Universidad Católica de Lima.

\section{Sobre el autor}

Rogelio Pérez-Perdomo es máster en Derecho de la Universidad de Harvard y doctor en Ciencias, mención Derecho, de la Universidad Central de Venezuela. Es profesor en la Universidad Metropolitana y profesor jubilado de la Universidad Central de Venezuela. Desde 1998 es profesor visitante frecuente de la Escuela de Derecho de la Universidad Stanford. Su correo electrónico es rperez@unimet.edu.ve. (iD) http://orcid.org/0000-0003-0086-0855. 
La Revista Pedagogía Universitaria y Didáctica del Derecho (RPUDD) es una publicación científica semestral que contribuye a la reflexión multidisciplinaria sobre pedagogía universitaria y didáctica del derecho, para la formación y consolidación de esta área de investigación; así como a la difusión de prácticas innovadoras en la enseñanza-aprendizaje del derecho considerando el contexto nacional e internacional. Es una publicación electrónica internacional con una codirección entre Brasil y Chile.

\author{
DIRECTORA \\ María Francisca Elgueta Rosas \\ Universidad de Chile \\ DIRECTOR \\ Renato Duro Dias \\ Universidad Federal de Rio Grande, Brasil \\ SITIO WEB \\ pedagogiaderecho.uchile.cl \\ CORREO ELECTRÓNICO \\ rpedagogia@derecho.uchile.cl \\ LICENCIA DE ESTE ARTÍ́CULO
}

Creative Commons Atribución Compartir Igual 4.0 Internacional

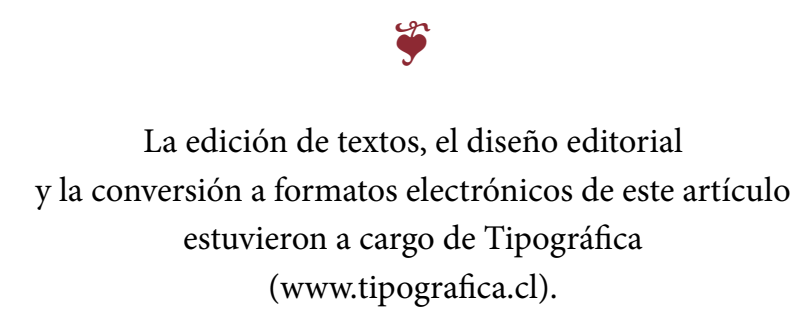

